Список литературы:

1. Дурновцев В.И., Савицкий П.Н. // Историки России XVIII-XX веков. Вып. 6. М., 1999. С. 111-123.

2. В поисках Евразии. Общественно-политическая и научная деятельность П.Н. Савицкого в годы эмиграции (1920-1938 гг.). Самара: Самарское книжное издательство, 2007. 280 с.

3. Трубецкой Н.С. Европа и Человечество // Наследие Чингисхана / Н.С. Трубецкой. М., 1999. С. 29-90.

4. Савицкий П.Н. Европа и Евразия // Континент Евразия / П.Н. Савицкий. М.: Аграф, 1997. С. 141-160.

5. Евразийство (опыт систематического изложения). Париж: Евразийское книгоиздательство, 1926. 80 с.

6. Евразийство (Формулировка 1927 г.) // Евразийская хроника. Париж, 1927. Вып. 9. С. 3-14.

7. Евразийство: декларация, формулировка, тезисы. Прага: Евразийское книгоиздательство, 1932. $30 \mathrm{c}$.

8. Савицкий П.Н. Географический обзор РоссииЕвразии // Континент Евразия / П.Н. Савицкий. М.: Аграф, 1997. С. 279-294.

9. Савицкий П.Н. В борьбе за евразийство // Континент Евразия / П.Н. Савицкий. М.: Аграф, 1997. C. $161-216$.

10. Савицкий П.Н. Евразийство // Континент Евразия / П.Н. Савицкий. М.: Аграф, 1997. С. 81-97.
11. Савицкий П.Н. Евразийство как исторический замысел // Континент Евразия / П.Н. Савицкий. М.: Аграф, 1997. С. 98-112.

12. Савицкий П.Н. Миграция культуры // Исход к Востоку. М.: Добросвет, 1997. С. 120-139.

13. Савицкий П.Н. Россия и эмиграция (культурно-историческая проблематика момента) // Новый град. Париж, 1938. № 13. С. 114-127.

14. Савицкий П.Н. Великороссия и Украина в русской культуре // Родное слово. Варшава. 1926. № 8. С. $10-14$.

15. Савицкий П.Н. Задание евразийства // Евразийский сборник. Прага, 1929. Кн. 6. С. 4-5.

16. Савицкий П.Н. Россия и латинство // Россия и латинство. Берлин: Евразийское книгоиздательство, 1923. C. 9-15.

17. Савицкий П.Н. Геополитические заметки по русской истории // Начертание русской истории / Г.В. Вернадский. СПб.: Лань, 2000. С. 285-310.

18. Савицкий П.Н. К обоснованию евразийства // Руль. 1922. № 349. 10 янв.

19. Савицкий П.Н. Подданство идеи // Континент Евразия / П.Н. Савицкий. М.: Аграф, 1997. С. 127-133.

20. Савицкий П.Н. Сила традиций и сила творчества // Континент Евразия / П.Н. Савицкий. М.: Аграф, 1997. С. 138-139.

\title{
CULTURAL PECULIARITIES OF RUSSIA-EURASIA IN SAVITSKIY'S CONCEPTION
}

(C) 2018

Bystryukov Vladimir Yurevich, candidate of historical sciences, associate professor of World History, Law and Methods of Teaching Department Samara State University of Social Sciences and Education (Samara, Russian Federation)

Abstract. The paper is aimed at P.N. Savitskiy's evaluation of cultural peculiarities of Russia-Eurasia. As a leader of the Eurasianism, he based his works on the main idea of the movement, which is the acceptance of «Eurasian» civilization. The influence of the Eurasia concept was the key point to the whole concept of the Eurasianship and the views of its individual representatives. The reality of a new continent existence determined the texts of Eurasianists, made it necessary to search for the system in a variety of features, and in the system itself to see an ordering that could not be connected with anything else than with a new continent. Cultural peculiarities of Russia-Eurasia were conditioned by its geographic expansion and its political factors. P.N. Savitskiy admitted the importance of the Orthodox Church in Russia-Eurasia history. According to P.N. Savitsky's mind Russia is «the third great Eurasian culture». However, the essentializing of Eurasia led to certain contradictions in the views of different representatives of the movement as well as of each Eurasian. According to the scientist, the manner of the new civilization development led inevitably to the «Eurasian» Russian future.

Keywords: Russian emigration; Eurasian movement; P.N. Savitsky; Eurasian civilization; Hellenism and Byzantinism; Culture of Russia; folklore; cultural peculiarities of Eurasianism; culture and ideology.

\section{МЕТОДОЛОГИЧЕСКИЕ ОСОБЕННОСТИ ИЗУЧЕНИЯ ИСТОРИЧЕСКОГО МОДЕЛИРОВАНИЯ АСИММЕТРИЧНЫХ КОНФЛИКТОВ}

(C) 2018

Малкин Станислав Геннадьевич, доктор исторических наук, доцент, заведующий кафедрой всеобщей истории, права и методики обучения

Самарский государственный соииально-педагогический университет (2. Самара, Российская Федераиия)

Аннотащия. В настоящей статье анализируются методологические особенности изучения роли наследия империй в политике ведущих держав в странах третьего мира сквозь призму исторического моделирования асимметричных конфликтов. Особое внимание уделено роли этого аналитического метода в определении курса внешней политики Великобритании и США после Второй мировой войны, в эпоху «холодной войны» во второй половине XX в. и «глобальной войны с террором» в начале XXI в. Обращается внимание не только на методологические ловушки (такие, как вероятность исследования проблемы по заданной переменной и терминологическая путаница), но и на исследовательские возможности, которые открывает такой подход в области исторического и политического анализа (такие, как, например, формирование более предметного представления об эволюции теории и практики международных отношений в условиях трансформации ми- 

ропорядка после Второй мировой войны). Отдельно оговаривается значение такого методологического приема, как историческое моделирование асимметричных конфликтов, в экспертных оценках внешней политики ведущих держав. Роль экспертного сообщества и академической экспертизы как важной составляющей той аналитической работы, которая им проводится в рамках исторического моделирования асимметричных конфликтов, также рассматривается в данной статье.

Ключевые слова: методология; историческое моделирование; асимметричный конфликт; постколониальная эпоха; колониальная система; экспертное сообщество; академическая экспертиза; Вторая мировая война; холодная война; глобальная война с террором; Великобритания; США; колониальные империи; страны третьего мира.

В 2016 г. исполнилось ровно сто лет соглашению Сайкса-Пико (Марка Сайкса и Франсуа Жоржа-Пико), предполагавшему раздел ближневосточных владений Османской империи между Великобританией и Францией после завершения Первой мировой войны. Значение этого секретного (до 1917 г.) документа трудно переоценить: именно эти договоренности (пусть и в несколько измененном виде по итогам решений Парижского мира 1919 г.) заложили сотрясаемые в наши дни основы политической конфигурации Ближнего Востока. В этой связи актуальность изучения наследия европейских колониальных империй представляется более чем очевидной.

При этом в свете распада колониальной системы после Второй мировой войны интерес мировых держав к региону стал заметнее в свете начавшейся холодной войны [1]. В начале XXI в. он объясняется реконфигурацией мирового порядка в связи с распадом биполярной системы международных отношений и борьбой с международным терроризмом. Это обстоятельство свидетельствует о необходимости нового понимания наследия империй в практической плоскости - как опыта удержания и контроля периферии, осмысливаемого многими экспертами на современном этапе в форме исторического моделирования асимметричных конфликтов.

Кроме того, в рамках актуального историко-политологического анализа необходимо уделять особое внимание методологическим особенностям исторического моделирования асимметричных конфликтов в тех случаях, когда речь идет об анализе процесса принятия решений в странах с высокой степенью включенности представителей академического мира в экспертное сообщество и актуальные общественнополитические дискуссии. Изучая роль колониального наследия европейских империй, необходимо отдавать себе отчет не только в том, каким языком, в каких терминах описывается этот феномен, но и учитывать влияние аналитических моделей на суждения и выводы экспертов.

В то же время, изучая процесс принятия решений в области международных отношений, всегда существует соблазн сосредоточиться на анализе экспертных мнений и позиций политической элиты. Чтобы избежать такого исследования по заданной переменной, следует проявлять методологическую осторожность и помнить о необходимости соотнесения позиций правящих кругов с общественным мнением. В этой связи можно вспомнить, как в начале 1960-х гг. министерство иностранных дел Великобритании инициировало исследование о том, что простые американцы думают об их стране. Эту задачу возложили на особенно многочисленные тогда в США британские консульства, и тем ошеломительнее был результат: рядовых граждан Америки «особые отношения» с Великобританией не волновали.
Еще одним методологическим затруднением в изучении восприятия колониальных империй после Второй мировой войны (и, прежде всего, с точки зрения их наследия в практической плоскости) является терминологическая путаница. Понятие «империя» употребляется многими авторами в качестве знаковой метафоры геополитического могущества современных государств, что лишает его конкретноисторического смысла и затрудняет выбор четких и непротиворечивых аналитических рамок. В этом смысле характерно, что наиболее яркими апологетами американского сверхдержавного и/или имперского лидерства выступают британцы - от дважды премьер-министра Великобритании сэра Уинстона Черчилля (апология «англо-саксонского мира») до влиятельного британского дипломата сэра Роберта Купера (призыв к «новому империализму») и широко признанного в академическом мире на обоих берегах Атлантики британского медийного историка Нэйла Фергюсона (геополитическое замещение Британской империи Соединенными Штатами), что наводит на определенные размышления не только о формах британского патриотизма (с точки зрения как политической ангажированности, так и академической честности), но и о движении этих идей в рамках «англо-саксонского мира» [2; 3, с. 475-498; 4; 5].

В целом такое превращение функций колониального знания в постколониальную эпоху свидетельствует о необходимости нового понимания не только его истории, но и наследия в практической плоскости - удержания и контроля территорий с опорой на исторический опыт - в том числе через обращение к историческому моделированию асимметричных конфликтов представителями военно-политических элит и экспертных сообществ ведущих держав современного мира [6].

Таким образом, ответ на вопрос о роли приобретенного в эпоху империй колониального знания в военно-политическом планировании и прогнозировании в Великобритании и США (англосаксонская модель представляет особый интерес, так как является наиболее цельной с точки зрения рецепции колониального опыта европейских держав в постколониальную эпоху) во второй половине XX - начале XXI в. позволит составить более предметное представление о теории и практике международных отношений в условиях трансформации миропорядка после Второй мировой войны, с переходом от эпохи глобальных колониальных империй к эпохе ядерных супердержав, и после холодной войны, в условиях распада биполярной системы и нарастающих противоречий между сторонниками концепции «глобального лидерства» и многополярного мира. Полученные результаты позволят сделать более аргументированными споры об особенностях и характере внешней политики ведущих держав современного 
мира, что имеет не только академическое, но и политическое значение.

Кроме того, постановка этой проблемы имеет большое значение для реконструкции процесса принятия решений в Великобритании и США по урегулированию асимметричных конфликтов с помощью исторического моделирования в качестве полноценного аналитического метода, предполагающего использование колониального опыта европейских держав (в том числе опыта накопления, систематизации и практического применения колониального знания) для выработки универсального рецепта «антиповстанческих операций» и «операций стабилизации» в странах третьего мира (эффективной организации контрпартизанской борьбы). Следовательно, в этой связи необходимо переосмыслить исторический опыт трансфера модели обеспечения внутренней безопасности в «опекаемые» государства, в том числе в рамках «гуманитарных интервенций» начала XXI в.

В этой связи перед учеными, решившими шагнуть на это поле исследований, стоят весьма амбициозные задачи. Во-первых, необходимо прояснить содержание понятий «колониальное знание» и «историческое моделирование» как основных аналитических категорий изучения наследия империй при анализе асимметричных конфликтов. Во-вторых, следует определить соотношение внутри- и внешнеполитического, социального, экономического и политического факторов накопления, систематизации и практического применения колониального знания до и после наступления эпохи деколонизации. В-третьих, требуется уточнить роль и значение, особенности взаимодействия участников применения колониального знания в асимметричных конфликтах в третьем мире (полиция, разведка, контрразведка) в рамках исторического моделирования. В-четвертых, стоит прояснить влияние национально-освободительных войн второй половины XX в. и «гуманитарных интервенций» начала XXI в. на характер и содержание применения колониального знания о странах третьего мира в рамках исторического моделирования асимметричных конфликтов. Наконец, в-пятых, требуется выявить особенности политики исторической памяти в связи с обращением к имперскому опыту европейских держав при историческом моделировании асимметричных конфликтов.

Следовательно, необходимо, прежде всего, переосмыслить исторический опыт трансфера модели обеспечения внутренней безопасности в различные страны современного мира в рамках «гуманитарных интервенций», «антиповстанческих операций» и «операций стабилизации» на основе комплексного изучения роли приобретенного в эпоху империй колониального знания в историческом моделировании асимметричных конфликтов как способе военнополитического анализа.

При этом особое внимание следует уделить не столько классической истории дипломатии и/или традиционной военной и политической истории, сколько особенностям процесса принятия решений представителями военно-политической элиты и экспертного сообщества через анализ роли приобретенного в эпоху империй колониального знания в историческом моделировании асимметричных конфликтов.
Характеризуя особенности участия ведущих держав в локальных конфликтах второй половины XX начала XXI вв., исследователи концентрируются, как правило, на объяснительных схемах теории асимметричных конфликтов [7]. В результате такого преимущественно политологического подхода упускается из виду отношение аналитиков и экспертов на государственной службе к «архиву» колониального знания европейских империй, их актуальному колониальному опыту. В этой связи обращение к роли колониального знания (понимаемого еще и как опыт империй) в урегулировании асимметричных конфликтов в странах третьего мира с методологической точки зрения имеет большое значение.

Труды зарубежных коллег в последнее время все чаще отражают тесную связь между властью метрополии и колониальным знанием через особую аналитическую призму - роль армии, полиции и разведки как колониальных институтов в умиротворении и социально-экономической модернизации и политической трансформации колоний [8-10]. На методологическом уровне речь идет о новом понимании роли армии, полиции и спецслужб в колониях и странах третьего мира в свете ее осмысления представителями военно-политических элит и экспертных сообществ в рамках исторического моделирования асимметричных конфликтов - на стыке истории колониального знания и «новой имперской истории», исторической науки, политологии и военно-политического анализа.

При этом разговор об институциональных особенностях армии и спецслужб в колониальном контексте в последнее время сосредоточен вокруг проблемы информационного обеспечения ее усилий по поддержанию порядка в империи - от этнографических штудий и картографирования подчиненных пространств к политической разведке, шпионажу и организации контрпартизанской борьбы. Все это показывает, до какой степени близки колониальные практики Нового и Новейшего времени. Вместе с тем такой ракурс исследования подтверждает необходимость методологического синтеза как на историографическом, так и на междисциплинарном уровнях современного гуманитарного знания.

Такой методологический подход к изучению заявленной темы позволяет скорректировать выводы постколониальных исследований о преимущественно силовом характере европейской имперской экспансии, пересмотреть традиционные взгляды на связь между эволюцией государственных институтов метрополий и колониальной политикой, подойти к анализу роли колониального знания с точки зрения аналитического инструментария принятия решений ведущих держав в постколониальную эпоху, в том числе в рамках метода исторического моделирования асимметричных конфликтов.

В результате можно будет, во-первых, понять, в каких случаях при изучении истории политики ведущих держав в странах третьего мира после Второй мировой войны мы сталкиваемся со стереотипами и подходами к политическим институтам, социальным структурам и процессам в бывших колониях, унаследованными от империй. Во-вторых, появится возможность уяснить, что из этого наследия безвозвратно ушло в прошлое, а что представляло собой 
Малкин С.Г.

Методологические особенности изучения исторического моделирования... 07.00 .00 - исторические науки и археология

устойчивую проблему, которую требовалось решать (социально-экономическая и политическая модернизация). Наконец, такая методология изучения асимметричных конфликтов второй половины XX - начала XXI в. позволяет ответить на вопрос о том, какие элементы этого наследия можно расценить как «скрытую угрозу», на которую не обратили должного внимания и которая далеко не всегда обсуждалась в собственных терминах (национальное пробуждение третьего мира, накрытое тенью холодной войны).

\section{Список литературы:}

1. Westad A.O. The Global Cold War: Third World Interventions and the Making of our Times. Cambridge: Cambridge University Press, 2007. 484 p.

2. Черчилль У. «Мускулы мира». Речь 5 марта 1946 г. в Фултоне // Мировой кризис / У. Черчилль. М.: Эксмо, 2003. 768 с.

3. Фергюсон Н. Империя. Чем современный мир обязан Британии. М.: Аст: CORPUS, 2013. 560 с.

4. Cooper R. The Post-modern State and the world order. London: Demos, 2002. 43 p.

\section{METHODOLOGICAL FEATURES
OF ASYMMETRIC CONFLICTS HISTORICAL MODELING STUDYING \\ METHODOLOGICAL FEATURES
OF ASYMMETRIC CONFLICTS HISTORICAL MODELING STUDYING}

(C) 2018

Malkin Stanislav Gennadyevich, doctor of historical sciences, associate professor, head of World History, Law and Methods of Teaching Department Samara State University of Social Sciences and Education (Samara, Russian Federation) mpire. New York: Penguin Press, 2004. 384 p.

6. Малкин С.Г. Колониальный опыт и стратегическое мышление США // Международные процессы. Т. 14, № 3 (46). Июль - сентябрь. 2016. С. 52-67.

7. Дериглазова Л. Асимметричный конфликт в современной американской политологии // Международные процессы. Т. 8, № 2 (23). Май - август 2010. C. 51-64.

8. Plank G. Rebellion and Savagery: The Jacobite Rising of 1745 and the British Empire. Philadelphia, 2006. 259 p.

9. Hevia J. The Imperial Security State. British Colonial Knowledge and Empire-Building in Asia. Cambridge, 2012. 304 p.

10. Thomas M. Empires of Intelligence. Security Services and Colonial Disorder after 1914. Berkeley and Los Angeles, 2008. 428 p.

Исследование выполнено за счет гранта Российского научного фонда (проект № 17-78-20029). Abstract. The following paper deals with methodological features of studying of empires legacy role in policy of
the leading powers in the countries of «the third world» through a prism of asymmetric conflicts historical modeling. The author pays special attention to the role of Great Britain and the USA foreign policy course defining after World War II during «Cold War» in the second half of the $20^{\text {th }}$ century and «Global War on Terror» at the beginning of the $21^{\text {st }}$ century. The author pays attention to methodological traps (such as the probability of the research problem on the given variable and terminological confusion) as well as to research opportunities which are opened by such approach in the field of the historical and political analysis (for example, evolution of the international relations theory and practice in the conditions of the world order transformation after World War II). Special attention is given to the value of such methodological reception as asymmetric conflicts historical modeling in expert estimates of the leading powers foreign policy. The paper also deals with the role of expert community and academic expertize as an important component of that analytical operation which is carried out within historical simulation of the asymmetrical conflicts.

Keywords: methodology; historical modeling; asymmetric conflict; postcolonial age; colonial system; expert community; academic expertize; World War II; «Cold War»; «Global War on Terror»; Great Britain; USA; colonial empires; countries of «the third world». 